\title{
Iron and selenium speciation in enriched adzuki bean sprouts after fractionation procedures by graphite furnace atomic absorption spectrometry
}

\begin{abstract}
Selenium (Se) and iron ( $\mathrm{Fe})$ are essential trace elements for human health, and their content in foods can vary significantly depending on the food characteristics, cultivation conditions (fertilizers, climate, and water), and geographical origin. The consumption of enriched edible sprouts is an effective strategy to combat nutritional deficiencies of $\mathrm{Fe}$ and Se. Notably, the daily Se intake range between essential and toxic levels is very narrow, inorganic Se species are more toxic than the organic forms and soluble Fe species are more bioaccessible than other species. Thus, a rapid method for determination of Fe species (soluble and inorganic) and a sensitive and selective micelle-mediated speciation and preconcentration method with elemental determination by GF AAS was developed to evaluate the effect of Fe and Se enrichment of adzuki bean sprouts, respectively, as well as the evaluation of the enrichment in the concentration of $\mathrm{Fe}$ and $\mathrm{Se}$ species that are potentially absorbed by the human organism. Fractionation procedures (extraction) were used for the separation of Fe species. The results indicated that the enrichment with $\mathrm{Fe}(\mathrm{III})$-EDTA favoured the translocation to the aerial part of the plant and increased $75 \%$ total Fe concentration in the stem. In the proposed methods for $\mathrm{Fe}$ (soluble and inorganic) speciation, it was found that the $\mathrm{Fe}$ enrichment increased the concentration of soluble $\mathrm{Fe}(50 \%)$ and inorganic $\mathrm{Fe}$ $(145 \%)$ in the edible part of the plant. Therefore, the Fe enrichment procedure applied is a good alternative to help reduce Fe deficiencies and the recommended daily intake. Extraction procedures were used for Se speciation, the method was based on CPE using nonionic surfactant Triton X-114 in the presence of dithizone as a chelating agent, which reacts selectively with $\mathrm{Se}(\mathrm{IV})$. The proposed method was successfully applied to the speciation and determination of organic (hydrophobic and hydrophilic) and inorganic (Se(IV) and $\mathrm{Se}(\mathrm{VI})$ ) species of Se in enriched adzuki bean sprouts. The obtained results show that hydrophilic organic Se species were predominant $(96 \pm 2 \mu \mathrm{g}$ $\mathrm{g}^{-1}$ ), and the enrichment procedure proved to be an appropriate alternative to reduce $\mathrm{Se}$ deficiency, due to the presence of Se bioaccessible species.
\end{abstract}

Volume 7 Issue 2 - 2018

\author{
Aline Pereira de Oliveira,' Cassiana Seimi \\ Nomura, ${ }^{2}$ Sidnei Gonçalves da Silva, ${ }^{3}$ Juliana \\ Naozuka \\ 'Departamento de Química, Universidade Federal de São Paulo, \\ Brazil \\ ${ }^{2}$ Instituto de Química, Universidade de São Paulo, Brazil \\ ${ }^{3}$ Centro de Ciências Exatas e Tecnologia, Universidade Federal \\ de Uberlândia, Brazil
}

Correspondence: Juliana Naozuka, Departamento de Química, Universidade Federal de São Paulo, Diadema, Sao Paulo, Brazil, Email jnaozuka@gmail.com,j.naozuka@unifesp.br

Received: February 01, 20I8| Published: March 12, 2018

Keywords: speciation, selenium, iron, enriched adzuki bean sprout

Abbreviations: GF AAS, graphite furnace atomic absorption spectrometry; CPE, cloud point extraction; ICP OES, inductively coupled plasma optical emission spectrometry; LOD, limit of detection; LOQ, limit of quantification

\section{Introduction}

The production of edible sprouts is a fast-growing segment of the food industry worldwide. Although several kinds of seeds may be eaten as sprouts, adzuki (Vigna angularis) and mung (Vigna radiata) beans are preferred and commonly used for sprout production. ${ }^{1}$ Studies have shown that grain germination increases the content of essential nutrients, such as minerals, vitamins, and proteins, and reduces the antinutritional factors, such as trypsin inhibitors, phenolic compounds, and nitrate, ${ }^{2}$ enhancing the quality and digestibility of the grains. Moreover, previous studies have clearly demonstrated that it is possible to enrich sprouts with essential elements to combat nutritional deficiencies, which is particularly important for populations in developing countries. ${ }^{3-6}$
The consumption of Se-enriched sprouts is a strategy to prevent the deficiency of this element in the human body, which is associated with various disorders including increased cholesterol levels, cardiomyopathy, muscular dystrophy, dysfunction of brain and liver, and Keshan disease, a disease affecting millions of people worldwide, particularly in China. ${ }^{7,8}$ The chemical form of dietary Se is important because it affects its bioavailability, toxicity, and chemoprotective activity. In nature, Se exists in the form of inorganic species, such as selenite [Se(IV)], selenate [Se(VI)], and selenides (e.g., $\mathrm{HgSe}$ ), or as organic species. ${ }^{9,10}$ In general, the inorganic forms are more toxic ${ }^{11,12}$ and less bioavailable to humans than the organic species. ${ }^{13}$ On the other hand, the consumption of Fe-enriched can increase iron consumption, which helps cellular homeostasis, oxygen transport and energy metabolism, as well as a cofactor of enzymes for mitochondrial respiratory chain and nitrogen fixation. ${ }^{14,15}$ It is important to point out that legumes have low concentrations of Fe species potentially absorbed by the human organism due to interactions of inorganic Fespecies, mainly bivalent cations, with phytic acid, tannins and other anti-nutrients, not being able to supply nutritional deficiencies. ${ }^{8,14,15}$ 
The success of elemental enrichment of sprouts depends on chemical species of the elements added to the culture medium, which may be absorbed, translocated, accumulated and converted in others chemical species potentially bioavailable. ${ }^{16,17}$ In this way, it is necessary to determine and identify the species formed after enrichment, establishing rapid analytical methods. Chemical speciation studies in the edible part of the enriched plant are important and may estimate the bioavailability, toxicity and elemental essentiality, ${ }^{18}$ promoting knowledge about the conscious use of these foods enriched with essential elements, such as $\mathrm{Fe}$ and Se. Therefore, the objective of this study was proposed a method to determine species of $\mathrm{Fe}$ (water soluble, acid soluble and inorganic) and $\mathrm{Se}$ (Se(IV), Se(VI), and organic (hydrophobic and hydrophilic)) in enriched adzuki bean sprouts, combining GF AAS with derivatization reactions or CPE, for $\mathrm{Fe}$ and Se, respectively.

\section{Material and methods}

\section{Instrumentation}

Total Fe and Se quantification was done by ICP OES, using an equipment (model iCAP 6300 Duo, Thermo Fisher Scientific, England) with axial and radial viewed plasma and a charge-injection device detector, which allows measurements from 166.25 to $847.00 \mathrm{~nm}$. An echelle polychromator purged with argon, a radiofrequency source of 27.12MHz, a Meinhard nebulizer combined with a cyclonic spray chamber was used. The instrumental parameters for ICP OES are given in Table 1.

Table I Instrumental conditions for Fe and Se determination by ICP OES

\begin{tabular}{ll}
\hline Power & $1250 \mathrm{~W}$ \\
\hline Plasma gas flow & $15 \mathrm{~L} \mathrm{~min}^{-1}$ \\
Intermediate gas flow & $1.0 \mathrm{~L} \mathrm{~min}^{-1}$ \\
Nebulizer gas flow & $0.45 \mathrm{~L} \mathrm{~min}^{-1}$ \\
Sample introduction & $1.5 \mathrm{~L} \mathrm{~min}^{-1}$ \\
$\begin{array}{l}\text { Analytical wavelength }- \text { axial view } \\
\text { (I) Atomic line }\end{array}$ & $\mathrm{Se}(\mathrm{I})=196.0 \mathrm{~nm}$ \\
(II) Ionic line & $\mathrm{Fe}(\mathrm{II})=259,8 \mathrm{~nm}$ \\
\hline
\end{tabular}

A ZEEnit 60 model atomic absorption spectrometer (AnalytikjenaAG, Jena, Germany) equipped with a transversely heated graphite atomizer, pyrolytically coated graphite tube, and a transversal Zeeman-effect background corrector was used for $\mathrm{Fe}$ and Se determination, after fractionation procedures and in phases obtained after CPE, respectively. All measurements were made using a hollow cathode lamp, and were based on integrated absorbance values. The optimized operating conditions of the spectrometer and the heating program are shown in Table 2. Argon 99.998\% ( $\left.\mathrm{v} \mathrm{v}^{-1}\right)$ (Air Liquide Brazil, São Paulo, Brazil) was used as a protective and purge gas. The digestion of samples for total Fe and Se determination was carried out in a closed-vessel microwave system (Speedwave-4, Berghof, Germany), equipped with 16 fluoropolymer vessels and a ceramic vessel jacket.
Table 2 Instrumental parameters and heating program for $\mathrm{Fe}^{\mathrm{a}}$ and $\mathrm{Se}^{\mathrm{b}}$ determination by GF AAS

\begin{tabular}{lllll} 
Step & $\mathbf{T}\left({ }^{\circ} \mathbf{C}\right)$ & Ramp (s) & Hold $(\mathbf{s})$ & $\begin{array}{l}\text { Ar flow } \\
\text { rate } \\
(\mathbf{m L} \\
\left.\mathbf{m i n}^{-1}\right)\end{array}$ \\
\hline Drying I & 100 & 10 & 15 & 250 \\
Drying II & 130 & 10 & 20 & 250 \\
Pyrolysis & $1200^{\mathrm{a}}, 900^{\mathrm{b}}$ & 100 & 20 & 250 \\
Atomization & $2300^{\mathrm{a}}, 2100^{\mathrm{b}}$ & $2300^{\mathrm{a}}, 2100^{\mathrm{b}}$ & 5 & 0 \\
Cleaning & 2500 & 1200 & 2 & 250
\end{tabular}

A thermostatic water bath (model Q226M2, Quimis, Brazil) at $95^{\circ} \mathrm{C}$ and $55^{\circ} \mathrm{C}$ was used for iron fractionation procedures with heating and selenium speciation with CPE experiments, respectively. An ultrasonic bath (model 75D Acquasonic, VWR Scientific Instruments, USA) was used to evaluate the effectiveness of total Se extraction for speciation studies. Phases separation was accelerated using a centrifuge (model Q222TM, Quimis, Brazil). For preliminary sample preparation, the stems (edible part) of the adzuki beans were separated and dried using a freeze dryer (Thermo Fisher Scientific, England). Homogenization of the culture medium was performed using an orbital shaker (model 0225M, Quimis, Brazil).

\section{Reagents and samples}

Adzuki beans (500g, a single brand) were purchased from the local market of Sao Paulo, Brazil. According to the manufacturer, the grains were produced in Brazil. All solutions were prepared from analytical reagent grade chemicals, using high-purity deionized water obtained from a Milli-Q water purification system (Millipore, USA) as the solvent. Analytical grade $65 \%\left(\mathrm{v} \mathrm{v}^{-1}\right) \mathrm{HNO}_{3}$ distilled in a quartz subboiling still (Marconi, Brazil) and 30\% $\left(\mathrm{v} \mathrm{v}^{-1}\right) \mathrm{H}_{2} \mathrm{O}_{2}$ (Merck, Germany) were used for sample digestion.

For Fe speciation were prepared two different precipitant reagents:

a. $25 \mathrm{~g}$ trichloroacetic acid (Merck, Germany) and $25 \mathrm{~mL}$ hydrochloride acid (Synth, Brazil) and

b. 25g trichloroacetic acid (Merck, Germany), 25g hydroxylamine hydrochloride (Merck, Germany), and $25 \mathrm{~mL}$ hydrochloride acid (Synth, Brazil). A final volume of $250 \mathrm{~mL}$ was completed by deionized water.

Titrisol standard solution of $1000 \mathrm{mg} \mathrm{L}^{-1}$ of $\mathrm{Fe}\left(\mathrm{FeCl}_{3}\right)$ (Merck, Germany) was used to prepare the reference analytical solutions in $0.1 \%\left(\mathrm{v} \mathrm{v}^{-1}\right) \mathrm{HNO}_{3}\left(10\right.$ to $80 \mu \mathrm{g} \mathrm{L}^{-1}$ and 1.25 to $80.0 \mathrm{mg} \mathrm{L}^{-1}$ for $\mathrm{Fe}$ determination by GF AAS and ICP OES, respectively).

For Se speciation, an acetone solution of dithizone (Merck, USA) was prepared. A $10 \%\left(\mathrm{v} \mathrm{v}^{-1}\right)$ ethanol solution (Merck, USA) containing $0.1 \mathrm{~mol} \mathrm{~L}^{-1} \mathrm{HNO}_{3}$ was used to dilute the surfactant-rich phase, and $\mathrm{Na}_{2} \mathrm{SeO}_{3}$ (Merck, Germany), $\mathrm{Na}_{2} \mathrm{SeO}_{4}$ (Sigma Aldrich, USA), selenomethionine (Sigma Aldrich, USA), $\mathrm{NaOH}$ (Merck, USA), and 
$\mathrm{HCl}$ (Merck, USA) were used for optimization of the CPE procedure. Titrisol standard solution of $1000 \mathrm{mg} \mathrm{L}^{-1}$ of $\mathrm{Se}\left(\mathrm{SeO}_{2}\right)$ was used to prepare the reference analytical solutions, by dilution with $0.1 \%$ (v $\left.\mathrm{v}^{-1}\right) \mathrm{HNO}_{3}$ for total Se determination by ICP OES, and with $0.1 \%(\mathrm{v}$ $\left.\mathrm{v}^{-1}\right) \mathrm{HNO}_{3}$ and $5 \%\left(\mathrm{v} \mathrm{v}^{-1}\right)$ Triton $\mathrm{X}-114$ or $2 \mathrm{mmol} \mathrm{L}^{-1}$ dithizone and $5 \%$ $\left(\mathrm{v} \mathrm{V}^{-1}\right)$ Triton X-114 for Se determination in the phases obtained after CPE by GF AAS. For Se determination by GF AAS, solutions of $20 \mathrm{~g}$ $\mathrm{L}^{-1} \mathrm{Pd}\left(\mathrm{NO}_{3}\right)_{2}$ (Merck) and $10 \mathrm{~g} \mathrm{~L}^{-1} \mathrm{Mg}\left(\mathrm{NO}_{3}\right)_{2}$ (Merck) were used to prepare the chemical modifier. Seed sterilization was performed using $\mathrm{NaClO}$ (Sigma Aldrich, USA) and a solution of $\mathrm{Na}_{2} \mathrm{SeO}_{4}$ (Sigma Aldrich, USA) or (NaFe(III)-EDTA (Sigma Aldrich, USA)) were used for the enrichment procedure.

\section{Cultivation of sprouts and preliminary sample preparation}

Cultivation of adzuki bean sprouts was carried out in triplicate for each treatment. The adzuki bean seeds were first cleaned with deionized water. After sterilization for $5 \mathrm{~min}$ in $12 \%\left(\mathrm{v} \mathrm{v}^{-1}\right) \mathrm{NaClO}{ }^{2}$ the seeds $(c a .5 \mathrm{~g})$ were cleaned again and soaked in deionized water (ca. $200 \mathrm{~mL}$ ) at room temperature for $24 \mathrm{~h}$, to promote the breaking of seed dormancy. ${ }^{19}$ Next, the seeds were placed on an absorbent cotton $(c a .3 \mathrm{~g})$ in a glass container (previously decontaminated with $10 \% \mathrm{~V} \mathrm{v}^{-1} \mathrm{HNO}_{3}$ ). The seeds were cultivated for 13 days in a portable greenhouse at $70 \%$ relative humidity, in the dark, and at a temperature of about 27 and $18^{\circ} \mathrm{C}$ during the day and night, respectively.

The germination of adzuki bean seeds was carried out with $20 \mathrm{~mL}$ of deionized water (control group), $20 \mathrm{~mL}$ of a $150 \mathrm{mg} \mathrm{L}^{-1} \mathrm{Fe}$ solution (3mg of Fe for Fe(III)-EDTA) or $20 \mathrm{~mL}$ of a $5 \mathrm{mg} \mathrm{L}^{-1}$ Se solution $(250 \mu \mathrm{g}$ of $\mathrm{Se}$ for $\mathrm{Na}_{2} \mathrm{SeO}_{4}$ ) in the growing medium. During germination, 13 days, all sprouts were soaked once a day with $20 \mathrm{~mL}$ of deionized water. The adzuki bean sprouts were collected and washed with deionized water, and the stem (edible part) was separated from the other plant parts. They were dried by lyophilization ( $c a .2$ days) and ground using a pestle and mortar (decontaminated) after freezing the samples in liquid nitrogen.

\section{Procedure for total Fe and Se determination}

The method characteristics for determination of total $\mathrm{Fe}$ and $\mathrm{Se}$ in enriched adzuki beans sprouts by ICP OES have been published by our group. ${ }^{16,17}$ For total $\mathrm{Fe}$ and Se determination, the adzuki beans sprouts were subjected to acid digestion in a closed-vessel microwave system. Sample masses ranging from 150 to $250 \mathrm{mg}$ were digested using a diluted oxidant mixture $\left(2 \mathrm{~mL} \mathrm{HNO}_{3}+1 \mathrm{~mL} \mathrm{H}_{2} \mathrm{O}_{2}+3 \mathrm{~mL}\right.$ $\mathrm{H}_{2} \mathrm{O}$ ).$^{20}$ The heating program consisted of three steps (temperature $/{ }^{\circ} \mathrm{C}$; $\mathrm{ramp} / \mathrm{min}$; hold/min): (1) $(140 ; 5 ; 1)$; (2) $(180,4,5)$; and (3) (220, 4, 10). The system was cooled by forced ventilation for $20 \mathrm{~min}$. Digestion was performed in duplicates for each sample, and the final volume of $10 \mathrm{~mL}$ was completed with deionized water.

\section{Fe speciation procedure}

For the speciation of soluble and inorganic Fe, the adapted procedure proposed by Oliveira et al. ${ }^{15}$ was used. Initially it was added $15 \mathrm{~mL}$ of deionized water to $400 \mathrm{mg}$ of stems (control and $\mathrm{Fe}$ enriched groups). These mixtures were agitated for $5 \mathrm{~min}$ at room temperature and their supernatants were separated by centrifugation at 4000rpm for $10 \mathrm{~min}$. The supernatants were analyzed by GF AAS, obtaining the concentration of $\mathrm{Fe}$ in the aqueous extract (Fe soluble and $\mathrm{Fe}$ associated with macromolecules). Subsequently, it was added $2.5 \mathrm{~mL}$ of a precipitant reagent 1 to $5 \mathrm{~mL}$ of the cloudy supernatant obtained after extraction with water, promoting the precipitation of macromolecules. ${ }^{21}$ The mixture was heated in a thermostatic bath at $95^{\circ} \mathrm{C}$, centrifuged at $4000 \mathrm{rpm}$ for $10 \mathrm{~min}$ and the supernatant was analyzed by GF AAS, obtaining the concentration of soluble Fe not associated with macromolecules. ${ }^{22}$

Another procedure was to add $2.5 \mathrm{~mL}$ of the precipitant reagent 2 to $5 \mathrm{~mL}$ of the aqueous extract. The mixture was heated in a thermostatic bath at $95^{\circ} \mathrm{C}$, centrifuged at $4000 \mathrm{rpm}$ for $10 \mathrm{~min}$ and the supernatant was analyzed by GF AAS. This procedure was applied to precipitate macromolecules and promote the reduction of $\mathrm{Fe}$ (III) to Fe (II). ${ }^{22,23}$ The determination of Fe in the obtained supernatants was performed by GF AAS and the heating program according to Table 2. The volume of $10 \mu \mathrm{L}$ of the samples or analytical solutions was injected into the graphite tube and no chemical modifier was used in the $\mathrm{Fe}$ determination. The calibration of the instrument was done with reference analytical solutions of concentrations ranging from 10 to $80 \mu \mathrm{g} \mathrm{L}^{-1}$ in $0.1 \%\left(\mathrm{v} \mathrm{v}^{-1}\right) \mathrm{HNO}_{3}$. After calibration, the supernatants obtained were previously diluted 20 times with deionized water before being analyzed. To evaluate possible matrix interference in elemental determination, the addition and recovery test was used. For this purpose, an analytical solution of $20 \mu \mathrm{g} \mathrm{L}^{-1}$ of Fe was added in the presence of the precipitant reagents 1 and 2, without and with addition of hydroxylamine, respectively.

\section{Se speciation procedure: initial extraction}

Two extractants were investigated for Se species extraction: deionized water and $1.0 \mathrm{~mol} \mathrm{~L}^{-1} \mathrm{NaOH}$. The dried and ground Seenriched sprouts $(250 \mu \mathrm{g})$ were subjected to initial extraction with $20 \mathrm{~mL}$ of the extractants. With the aim to extract all Se species, the extraction was tested in a thermostatic water bath at $80^{\circ} \mathrm{C}$ and in an ultrasonic bath, each for $30 \mathrm{~min}$. The supernatant (aqueous extract) was isolated by centrifugation at $4000 \mathrm{rpm}$ for $15 \mathrm{~min}$.

\section{Se speciation procedure: CPE}

A volume of $10 \mathrm{~mL}$ of the aqueous extract (see "Initial extraction") was mixed with $1 \mathrm{~mL}$ of $1 \%\left(\mathrm{v} \mathrm{v}^{-1}\right)$ nonionic surfactant Triton $\mathrm{X}-114$, and the mixture was heated in a thermostatic water bath at $55^{\circ} \mathrm{C}$ for $20 \mathrm{~min}$. Next, the obtained surfactant-rich phase was separated by cooling in an ice-water bath for $20 \mathrm{~min}$ followed by centrifugation at $4000 \mathrm{rpm}$ for $15 \mathrm{~min}$. In this phase, the hydrophobic organic Se species were determined.

The surfactant-poor phase was subjected to a second CPE, using $1 \mathrm{~mL}$ of $1 \%\left(\mathrm{v} \mathrm{v}^{-1}\right)$ Triton $\mathrm{X}-114$ and $0.2 \mathrm{~mL}$ of $2 \mathrm{mmol} \mathrm{L}^{-1}$ dithizone. In this second extraction, the $\mathrm{pH}$ of the medium was evaluated, ranged from 1 (adjusted by $0.1 \mathrm{~mol} \mathrm{~L}^{-1} \mathrm{HCl}$ ) to 9 (adjusted by $0.1 \mathrm{~mol}$ $\mathrm{L}^{-1} \mathrm{NaOH}$ ), using solutions containing $500 \mu \mathrm{gL}^{-1}$ of Se from $\mathrm{Se}(\mathrm{IV})$, $\mathrm{Se}(\mathrm{VI})$, and Se-methionine (Se-Met). The mixture was kept in a thermostatic water bath at $55^{\circ} \mathrm{C}$ for $20 \mathrm{~min}$. Formation and separation of the surfactant-rich and -poor phases was achieved by cooling in an ice-water bath for $20 \mathrm{~min}$ followed by centrifugation at $4000 \mathrm{rpm}$ 
for $15 \mathrm{~min}$. After optimization of the CPE procedure, Se(IV) was determined in the surfactant-rich phase.

A second aliquot of $5 \mathrm{~mL}$ of the aqueous extract was subjected to CPE using only $1 \mathrm{~mL}$ of $1 \%\left(\mathrm{v} \mathrm{v} \mathrm{v}^{-1}\right)$ nonionic surfactant Triton $\mathrm{X}-114$. After phase separation, the surfactant-poor phase containing hydrophilic organic and inorganic Se species was heated to $55^{\circ} \mathrm{C}$ for $5 \mathrm{~min}$ in the presence of $\mathrm{HCl}$. The $\mathrm{HCl}$ concentration was evaluated, ranged from 1 to $6 \mathrm{~mol} \mathrm{~L}^{-1}$, using a solution of $\mathrm{Se}(\mathrm{VI})\left(500 \mu \mathrm{g} \mathrm{L}^{-1}\right)$. The HCl-treated surfactant-poor phase was diluted to $10 \mathrm{~mL}$ with deionized water and subjected to CPE using $1 \mathrm{~mL}$ of $1 \%\left(\mathrm{v} \mathrm{v}^{-1}\right)$ Triton $\mathrm{X}-114$ and $0.2 \mathrm{~mL}$ of $2 \mathrm{mmol} \mathrm{L}^{-1}$ dithizone. ${ }^{24}$ Inorganic Se species were determined in the surfactant-rich phase.

Se determination was carried out by GF AAS in the different phases obtained after CPE. Prior to analysis, the surfactant-rich phases were diluted with a $10 \%\left(\mathrm{v} \mathrm{v}^{-1}\right)$ ethanol solution containing $0.1 \mathrm{~mol} \mathrm{~L}^{-1} \mathrm{HNO}_{3}$. Moreover, $10 \mu \mathrm{L}$ of chemical modifier $(5 \mu \mathrm{g}$ $\mathrm{Pd}+3 \mu \mathrm{g} \mathrm{Mg}$ ) was co-injected with $10 \mu \mathrm{L}$ of extract/phase or analytical solution. The thermal behavior of Se in the absence and presence of Triton and dithizone was studied. The pyrolysis temperature was optimized, ranging from 400 to $1400^{\circ} \mathrm{C}$ with increments of $100^{\circ} \mathrm{C}$ at an atomization temperature of $2300^{\circ} \mathrm{C}$. At the optimum pyrolysis temperature, the atomization temperature was studied from 1600 to $2300^{\circ} \mathrm{C}$ with increments of $100^{\circ} \mathrm{C}$. The chemical modifier was always co-injected during the analysis. Instrument calibration was performed using analytical solutions with concentrations ranging from 20 to $180 \mu \mathrm{g} \mathrm{L}^{-1}$ in $0.1 \%\left(\mathrm{v} \mathrm{v}^{-1}\right) \mathrm{HNO}_{3}$ or $1 \%\left(\mathrm{v} \mathrm{v}^{-1}\right)$ Triton $\mathrm{X}-114$ and $2 \mathrm{mmol}$ $\mathrm{L}^{-1}$ dithizone. Chemical interferences during Se determination by GF AAS were evaluated by addition and recovery tests, adding a solution Table 3 Characteristics method for Fe and Se determination by GFAAS of $40 \mu \mathrm{g} \mathrm{L}^{-1} \mathrm{Se}(\mathrm{Se}(\mathrm{IV}), \mathrm{Se}(\mathrm{VI})$, or Se-Met) in the surfactant phases.

\section{Results and discussion}

\section{Analytical methods characteristics}

For Fe and Se total determination by ICP OES, the analytical characteristics and evaluation of the chemical interferences and accuracy are shown in the previous worked of the research group. ${ }^{16,17}$ The Fe and Se species determination was conducted by GF AAS. The characteristic parameters of the analytical calibration curves (linear range, correlation coefficient $\left(\mathrm{R}^{2}\right)$, LOD and LOQ) are shown in Table 3, as well as the results of recovery of the addition and recovery test that was used to verify chemical interferences in the $\mathrm{Fe}$ and Se determination by GF AAS. The LOD was calculated from the standard deviation of 10 measurements of the analytical blank sample $\left(3 \times \sigma_{\text {blank }}\right.$, where $\sigma$ is the standard deviation), and the LOQ was calculated as $3.3 \times$ LOD $^{25}$ The values were obtained in $\mu \mathrm{g} \mathrm{g}^{-1}$ For Fe, the LOD and LOQ values were obtained considering a $400 \mathrm{mg}$ sample and a final volume $10 \mathrm{~mL}$ and $15 \mathrm{~mL}$ for aqueous extract and precipitant reagents, respectively. For Se, was considered a sample mass of 200 $\mathrm{mg}$ and a final volume of $10 \mathrm{~mL}$ for total Se determination, and a sample mass of $100 \mathrm{mg}$ and a final volume of $2 \mathrm{~mL}$ for Se speciation. The recoveries ranged between $82(\mathrm{Se}(\mathrm{VI})$ ) and 115 (iron soluble in water) $\%$, indicating the absence of chemical interferences during $\mathrm{Fe}$ and Se determination in the presence of the various reagents used for fractionation and CPE, respectively. According to the US Food \& Drug Administration for elemental determination by spectrometric techniques, the recovery tolerance for food samples ranges from 80 to $120 \% .^{26}$

\begin{tabular}{|c|c|c|c|c|c|c|c|}
\hline & & & $\begin{array}{l}\text { Linear range } \\
\left(\mu \mathrm{L}^{-1}\right)\end{array}$ & $\mathbf{R}^{2}$ & $\begin{array}{l}\text { LOD } \\
\left(\mu g^{-1}\right)\end{array}$ & $\begin{array}{l}\text { LOQ } \\
\left(\mu g g^{-1}\right)\end{array}$ & $\begin{array}{l}\text { Recovery } \\
(\%)\end{array}$ \\
\hline \multirow{3}{*}{ Se } & Inorganic selenium & $\begin{array}{l}\mathrm{Se}(\mathrm{IV}) \\
\mathrm{Se}(\mathrm{VI})\end{array}$ & $20-180$ & 0.9994 & $\begin{array}{l}0.26 \\
0.13\end{array}$ & $\begin{array}{l}0.79 \\
0.39\end{array}$ & $\begin{array}{l}96 \\
82\end{array}$ \\
\hline & \multirow{2}{*}{ Organic selenium } & Hydrophilic & \multirow{2}{*}{$20-180$} & \multirow{2}{*}{0.9962} & 4.29 & 12.88 & $98^{\mathrm{a}}$ \\
\hline & & Hydrophobic & & & 0.25 & 0.75 & $N D^{b}$ \\
\hline & Water & & & & 0.036 & 0.118 & 0.115 \\
\hline \multirow{2}{*}{$\mathrm{Fe}$} & Precipitant reagent I & & $10-80$ & 0.9983 & 0.032 & 0.105 & 0.108 \\
\hline & Precipitant reagent 2 & & & & 0.027 & 0.090 & 0.99 \\
\hline
\end{tabular}

addition of $80 \mu \mathrm{g} \mathrm{L}^{-1}$ Se-Met; ${ }^{\mathrm{b}} \mathrm{ND}=$ not determined.

\section{Fe speciation in enriched sprouts}

The Fe determination in the aqueous extract and after addition of different precipitant reagents was performed by GF AAS. The soluble Fe concentration was obtained in the supernatant from the extraction with water, $\mathrm{Fe}$ not associated with macromolecules (including inorganic $\mathrm{Fe}$ ) in the supernatant of the extraction with the precipitant reagent 1 , and the concentration of $\mathrm{Fe}$ species not associated to macromolecules and which are not inorganic Fe species, such as the association of $\mathrm{Fe}$ to soluble fibers, in the supernatant of extraction with precipitant reagent 2 . The Fe concentrations in the supernatants of the aqueous extract and the different precipitant reagents with and without addition of hydroxylamine in the samples of bean sprouts (control and Fe-enriched group), are presented in Table 4.
It has been found that soluble $\mathrm{Fe}$ (aqueous extract) is a fraction of total $\mathrm{Fe}$ in both culture conditions (control and Fe-enriched group). The enrichment procedure increased the Fe concentration in the aqueous extract, but when compared to the total concentration a decrease in the soluble Fe after enrichment (49\% (control) and $42 \%$ (Fe-enriched)) was observed. It is possible that the decrease in the concentration of water-soluble proteins (albumins) after enrichment with $\mathrm{Fe}(\mathrm{III})-\mathrm{EDTA}$, is one of the causes for the decrease in the soluble Fe percentage.

After addition of the precipitant reagents 1 and 2, it was possible to quantify soluble non-macromolecular and inorganic Fe, respectively. The Fe concentration in the supernatant after addition of precipitant reagent 1 reduced $80 \%$ (control) and $82 \%$ (enriched) when compared 
to the Fe concentration in the aqueous extract. The trichloroacetic acid added to the precipitant reagent was used as a precipitant of proteins and peptides, and its efficiency in the macromolecules precipitation has been reported by Carreira et al. ${ }^{27}$ Therefore, it is possible to deduce that in the stem of the Fe-enriched sprouts and control group there is a significant amount of $\mathrm{Fe}$ associated with macromolecules. In addition, it was also verified that the enrichment did not significantly alter the percentage of total $\mathrm{Fe}$ associated with macromolecules.

Table 4 Concentrations of iron in the supernatants and the effect of hydroxylamine

\begin{tabular}{|c|c|c|}
\hline & \multicolumn{2}{|c|}{$\begin{array}{l}\text { Concentration of } \mathrm{Fe}\left(\mu \mathrm{g} \mathrm{g}^{-1}\right) \pm \\
\text { standard deviation }(n=3)\end{array}$} \\
\hline & Control & $\mathrm{Fe}(\mathrm{III})-\mathrm{EDTA}$ \\
\hline Total & $89 \pm 1$ & $156 \pm 1$ \\
\hline Aqueous extract & $44 \pm 2$ & $66 \pm 1$ \\
\hline $\begin{array}{l}\text { Precipitant reagent I } \\
\text { (without hydroxylamine, } \\
\mathrm{pH}<\mathrm{I} \text { ) }\end{array}$ & $8.6 \pm 0.8$ & $12 \pm 1$ \\
\hline $\begin{array}{l}\text { Precipitant reagent } 2 \\
\text { (with hydroxylamine, } \\
\mathrm{pH}=5,5 \text { ) }\end{array}$ & $5.5 \pm 0.1$ & $4.0 \pm 0.7$ \\
\hline Inorganic $\mathrm{Fe}^{\mathrm{a}}$ & $3.1 \pm 0.8$ & $7.6 \pm 0.8$ \\
\hline
\end{tabular}

asubtraction of the Fe concentration in the extract with hydroxylamine of the extract without hydroxylamine.

In the absence of hydroxylamine, it is possible to obtain the concentration of $\mathrm{Fe}$ associated with macromolecules, whereas when adding hydroxylamine, the total inorganic $\mathrm{Fe}$ concentration was determined. Comparing the $\mathrm{Fe}$ concentration after the addition of the precipitant reagents 1 and 2, it was verified that the Fe concentration decreased 36 and $65 \%$ in the control and enriched groups, respectively.

According to Quinteros et al., ${ }^{22}$ Kosse et al. ${ }^{23}$ the addition of hydroxylamine to the precipitant reagent promotes the reduction of $\mathrm{Fe}(\mathrm{III})$ to $\mathrm{Fe}$ (II) ions and studies have shown that $\mathrm{Fe}$ (II) ions interact with macromolecules that are precipitated with the addition of trichloroacetic acid and other matrix components, such as antinutritional components. ${ }^{8,15}$ The polyphenols, such as tannins, may react with bivalent metal ions, such as Fe(II) through its carboxylic and hydroxyl groups forming insoluble complexes and reducing the absorption of non-heme Fe. ${ }^{14,15,17}$ Furthermore, another antinutrient present in legumes, the phytic acid has high potential chelating. This compound exhibits 12 ionizable protons and can interact with metal ions. Phytate, abundant in legumes, is one of the main inhibitors of non-heme iron absorption, binds mainly to bivalent metal ions and forms insoluble salts, altering the solubility, functionality, digestibility and absorption of $\mathrm{Fe}^{28}$ In acid or neutral media, such as the precipitant reagent $2(\mathrm{pH}=5.5)$, the 6 phosphate groups of the phytic acid molecule expose its 12 negative charges, favoring the direct or indirect complexation of this molecule with bivalent cations of $\mathrm{Fe}(\mathrm{II})$, starch, proteins, and enzymes. ${ }^{29}$ In addition, the interaction of $\mathrm{Fe}(\mathrm{II})$ ion with phytate molecules is more effective at lower $\mathrm{pH}$, on the other hand, the phytate-Fe(III) complex is more stable when the ligand is deprotonated due to the high $\mathrm{Fe}(\mathrm{III})$ (central atom) charge which produces a more effective interaction with phytate and, consequently, more protons are replaced in the ligand at higher $\mathrm{pH}^{30}$

Therefore, due to significant decrease in the $\mathrm{Fe}$ concentration of extracts without and with hydroxylamine of the control and Fe- enriched group it is possible to infer that the hydroxylamine reacts only with $\mathrm{Fe}$ (III) ions reducing them to $\mathrm{Fe}(\mathrm{II})$, which is associated with antinutrients, such as polyphenols and phytates, forming products that are not extracted in water or precipitate together the macromolecules when adding trichloroacetic acid. Thus, it is possible to quantify total inorganic $\mathrm{Fe}$ in the stem of the azuki bean sprouts, subtracting the Fe concentration in the extract with hydroxylamine of the extract without hydroxylamine (Table 4). It is important to point out that the concentration of $\mathrm{Fe}$ in the extract with hydroxylamine is due to other soluble species of $\mathrm{Fe}$, such as Fe associated with compounds of low molecular weight and that are not precipitated by the action of trichloroacetic acid.

The enrichment increased the concentration of inorganic Fe. Non-heme Fe can be found in foods of plant origin such as inorganic $\mathrm{Fe}(\mathrm{II})$ and/or Fe(III). The absorption of these iron species by the human organism is less than $5 \%$. So, although bean sprouts cannot be considered as a plant source rich in non-heme iron, Fe(III)EDTA enrichment may assist in increasing of Fe species available for absorption, which was able to increase in 75,50 and $145 \%$ the concentration of total, soluble and inorganic Fe, respectively.

\section{Se speciation in enriched sprouts}

Optimization of the total Se extraction: Se species separation by extraction must be considered carefully in order to maintain the integrity of the species. To effectively release analytes from the matrix without alteration, two extractants, namely, deionized water and $1.0 \mathrm{~mol} \mathrm{~L}^{-1} \mathrm{NaOH}$, and different conditions, namely, heating in a thermostatic water bath and ultrasonic treatment, were studied, and the results are shown in Table 5.

Statistical tests were used to compare the total Se concentration obtained after acid digestion in a microwave oven by extraction using different extractants (deionized water or $\mathrm{NaOH}$ solution) or systems (water bath or ultrasound). The Student's $t$-test (95\% confidence) and $p$-values $(<0.05)$ did not show significant differences between the obtained results. A CPE procedure using deionized water and a thermostatic water bath was selected for Se speciation.

Table 5 Evaluation of the total selenium extraction method

\begin{tabular}{|c|c|c|c|}
\hline \multirow{2}{*}{ Extractant } & \multirow{2}{*}{ Extraction method } & \multicolumn{2}{|c|}{$\begin{array}{l}\text { Concentration ( } \mu \mathrm{g} \\
\left.\mathrm{g}^{-1}\right) \pm \text { standard deviation } \\
(\mathrm{n}=3)\end{array}$} \\
\hline & & $\begin{array}{l}\text { After acid } \\
\text { digestion }\end{array}$ & $\begin{array}{l}\text { After } \\
\text { extraction } \\
\text { procedure }\end{array}$ \\
\hline \multirow{2}{*}{$\mathrm{H}_{2} \mathrm{O}$} & Thermostatic water-bath & $105 \pm 2$ & $93 \pm 4$ \\
\hline & Ultrasound-assisted & $105 \pm 2$ & $92 \pm 8$ \\
\hline \multirow{2}{*}{$\mathrm{NaOH}$} & Thermostatic water-bath & $105 \pm 2$ & $97 \pm 5$ \\
\hline & Ultrasound-assisted & $105 \pm 2$ & $94 \pm 6$ \\
\hline
\end{tabular}

For total protein extractions, $\mathrm{NaOH}$ has been widely used, but it is not protein-specific. ${ }^{31}$ As the proposed method aims at speciation of organic and inorganic Se species, the use of $\mathrm{NaOH}$ extractant can be harsh mainly for inorganic Se species. Moreover, previous studies showed that $\mathrm{Se}(\mathrm{IV})$ can be determined by co-precipitation, after precipitation of metal hydroxides, such as iron(III), lanthanum, or magnesium hydroxides. ${ }^{12}$ Thus, Se(IV) determination would not be possible by $\mathrm{CPE}$ with $\mathrm{NaOH}$. 
Preservation of Se species was also the reason for choosing a thermostatic water bath over ultrasonic treatment. The latter is known to cause cavitation, a physical process by which tiny gas bubbles are generated. Upon implosion, these bubbles behave as microreactors with temperatures and pressures reaching about $5000^{\circ} \mathrm{C}$ and $100 \mathrm{~atm}$, respectively. The power of ultrasonic waves has raised concerns for applications in chemical speciation, because it can result in the formation of radical species. ${ }^{32}$ In the determination of Se-methylselenocysteine and Se-methionine in Se-enriched plants (Allium sativum and Brassica juncea), the effect of the ultrasonic probe on the extraction using different extractants (namely, $\mathrm{HCl}$, protease, and ammonium acetate buffer) was evaluated, and a lower amount of Se was extracted with $\mathrm{HCl}$ and ammonium acetate buffer when an ultrasonic probe was used. In the case of Se speciation, the application of an ultrasonic probe provided negligible species degradation. ${ }^{33}$

\section{Evaluation of pyrolysis and atomization temperatures}

The heating program for Se determination by GF AAS was optimized in the presence of the reagents used for CPE. Pyrolysis and atomization temperature curves were obtained using analytical solutions of $\mathrm{Se}$ in Triton $\mathrm{X}-114$ and dithizone, co-injected with the chemical modifier $(\mathrm{Pd}+\mathrm{Mg})$, and are shown in Figure 1. It was observed that Se species were thermally stable up to $900^{\circ} \mathrm{C}$. At a pyrolysis temperature below $400^{\circ} \mathrm{C}$, absorption could not be measured because of the high background signals, mainly due to the presence of surfactant and complexing agent. The optimum atomization temperature was $2100^{\circ} \mathrm{C}$, because at lower temperatures double analytic signals were observed.

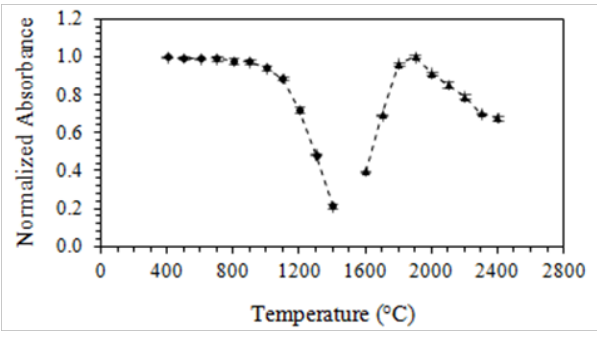

Figure I Pyrolysis $(\bullet)$ and atomization $(\boldsymbol{\Delta})$ temperatures curves. $(40 \mu \mathrm{g}$

$\left.\mathrm{L}^{-1}\right) \mathrm{Se}(\mathrm{IV})$, chemical modifier, Triton X-I I4 and dithizone.

Upon addition of the $\mathrm{Pd} / \mathrm{Mg}$ mixture, a high pyrolysis temperature $\left(900^{\circ} \mathrm{C}\right)$ was achieved, due to the formation of a non-volatile, solid solution between Se and Pd, which allowed the elimination/ minimization of the matrix and surfactant and complexing agent. The chemical modifier is essential for Se determination by GF AAS because, in its absence and at temperatures above $130^{\circ} \mathrm{C}$, Se volatilizes in the form of oxides $\left(\mathrm{SeO}\right.$ and $\left.\mathrm{SeO}_{2}\right) \cdot{ }^{34}$

\section{Optimization of the Se speciation procedure}

CPE is based on the formation of turbidity and the subsequent separation of hydrophilic and hydrophobic components. ${ }^{35}$ Aqueous solutions of nonionic surfactant materials become cloudy when their temperature reaches the cloud point, and the analyte collapses with a small volume by a surface-active material. ${ }^{36}$ This leads to a large preconcentration factor due to a very small volume of micellar phase binding the analyte that was dispersed in the original matrix. ${ }^{37}$ Thus, CPE is not only a preconcentration process but also a separation method, and has been applied for speciation of Se in trace levels. ${ }^{38}$

The solution $\mathrm{pH}$ plays an important role in the formation of metal-chelate complexes, their chemical stability, and subsequent extraction. Only Se(IV) reacts with dithizone to form a hydrophobic complex, which is then trapped by surfactant micelles and separated from the aqueous phase. ${ }^{39}$ The $\mathrm{pH}$ effect on the extraction of different Se species (Se(VI), Se(IV), and Se-methionine) was investigated, and the results are shown in Figure 2. The extraction efficiency (\%) was calculated from the initial Se concentration with respect to that after CPE. Se(IV) extraction was higher at $\mathrm{pH} 2$, which was used in subsequent studies. At $\mathrm{pH}$ values above 3, a significant decrease in the $\mathrm{Se}(\mathrm{VI})$ analytical signal was observed, due to dithizone instability under these conditions. ${ }^{24}$ For the other Se species (namely, Se(VI) and Se-methionine), as expected, complex formation did not occur, and the CPE efficiency was zero, confirming the selective reactivity of dithizone toward Se(IV).

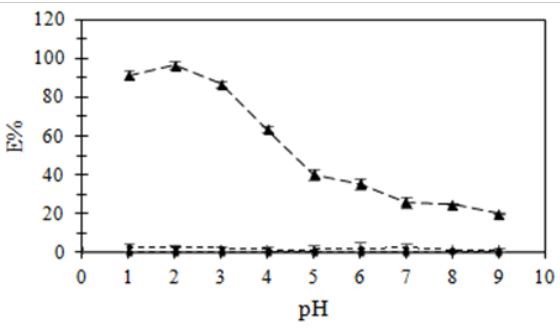

Figure 2 Effect of $\mathrm{pH}$ on complexation of $\mathrm{Se}(\mathrm{IV})(\mathbf{\Delta}), \mathrm{Se}(\mathrm{VI})(\bullet)$ and SeMet (ם) with dithizone and cloud point extraction efficiency.

Dithizone and Triton X-114 concentrations as well as equilibration temperature and incubation time are important parameters for CPE, which should be optimized to achieve complete reaction, easy phase separation, and efficient preconcentration. ${ }^{37}$ However, several studies have been reported on the application of CPE using Triton X-114 and complexing agents such as dithizone for total Se determination and fractionation (organic and inorganic species)..$^{24,34,36-39}$ Hence, in this work, these parameters were not investigated, and the conditions established by Sun et al. ${ }^{24}$ were applied.

The effect of $\mathrm{HCl}$ concentration on the reduction of $\mathrm{Se}(\mathrm{VI})$ to $\mathrm{Se}(\mathrm{IV})$ was examined, as shown in Figure 3. The $\mathrm{HCl}$ solution was added to the surfactant-poor phase obtained after the first CPE using only Triton X-114, and the mixture was heated, subjected to a second CPE in the presence of dithizone, and analyzed by GF AAS. The $\mathrm{HCl}$ can serve as a reducing agent for $\mathrm{Se}(\mathrm{VI})$ reduction, by the following chemical reaction: $\mathrm{HSeO}_{4}^{-}+3 \mathrm{H}^{+}+2 \mathrm{Cl}^{\leftrightarrows} \leftrightarrows \mathrm{H}_{2} \mathrm{SeO}_{3}+\mathrm{H}_{2} \mathrm{O}+\mathrm{Cl}_{2}$. Other reducing agents have also been proposed in the literature, such as $\mathrm{TiC}_{3}$, $\mathrm{KI}$, thiourea, $\mathrm{HBr}$, and a mixture of $\mathrm{HCl}$ and $\mathrm{HBr}^{40}$ Using only $\mathrm{HCl}$, efficient $\mathrm{Se}(\mathrm{VI})$ reduction occurred at high $\mathrm{HCl}$ concentrations, ${ }^{44}$ as shown in Figure 3, and the highest extraction efficiency was observed using a $6.0 \mathrm{~mol} \mathrm{~L}^{-1} \mathrm{HCl}$ solution. However, $4.0 \mathrm{~mol} \mathrm{~L}^{-1}$ was chosen as the optimal $\mathrm{HCl}$ concentration, because at this value the extraction efficiencies were statistically indistinguishable (Student's $t$-test and $95 \%$ confidence).

After optimization of the conditions, the hydrophobic organic Se species were determined in the surfactant-rich phase after CPE in the absence of dithizone. The surfactant-poor phase containing hydrophilic organic and inorganic Se species was subjected to a 
second $\mathrm{CPE}$ in the presence of dithizone for $\mathrm{Se}(\mathrm{VI})$ determination. For inorganic Se species determination, the surfactant-poor phase was first subjected to $\mathrm{Se}(\mathrm{VI})$ reduction by addition of $\mathrm{HCl}$ and heating, followed by CPE in the presence of dithizone. Se(VI) species were determined by subtracting the $\mathrm{Se}(\mathrm{IV})$ concentration from the total concentration of inorganic Se species. Moreover, the hydrophilic organic Se species were quantified by subtracting the Se concentration in the surfactant-poor phase obtained after CPE without dithizone from the total concentration of inorganic Se species.

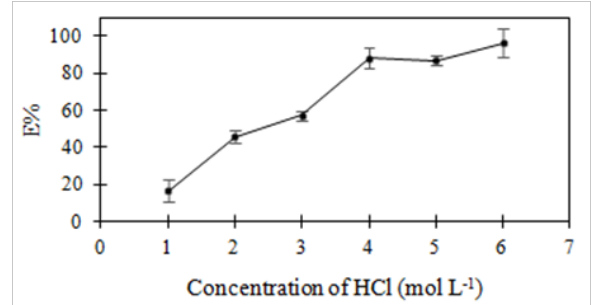

Figure 3 Effect of $\mathrm{HCl}$ concentration on reduction of $\mathrm{Se}(\mathrm{VI})$ to $\mathrm{Se}(\mathrm{IV})$. CPE conditions: I\% v v-I Triton X-II4 and $2 \mathrm{mmol} \mathrm{L-1}$ dithizone.

\section{Analysis of the enriched sprouts}

Se enrichment of adzuki bean sprouts is an inexpensive strategy to improve the quality and nutritional value of food, and could also help combat nutritional deficiencies. The success of the enrichment is related not only to the increase in the total Se concentration, but also to the formation of bioaccessible and bioavailable species. According to the literature, organic Se species are more bioavailable and less toxic than the inorganic species, ${ }^{11-13}$ and Se(IV) is more toxic than $\mathrm{Se}(\mathrm{VI}) .{ }^{40}$ For the cultivation of Se-enriched sprouts, $\mathrm{Se}(\mathrm{VI})$ was used, which is absorbed by plant roots through the sulfate carriers and easily distributed to the aerial parts of the plant. In plant metabolism, $\mathrm{Se}(\mathrm{VI})$ is initially reduced by the catalysis of ATP sulfurylase to Se(IV), which is assimilated into organic compounds of Se..$^{41}$ Thus, enriched adzuki bean sprouts can be safely used as dietary supplements, and can be considered as an appropriate alternative to reduce Se deficiency. The results demonstrating the applicability of the procedure to $\mathrm{Se}$ speciation in enriched adzuki bean sprouts are summarized in Table 6.

Table 6 Selenium speciation results in enriched adzuki beans sprouts

\begin{tabular}{lll}
\hline & & $\begin{array}{l}\text { Se concentration }(\boldsymbol{\mu g} \\
\left.\mathbf{g}^{-1}\right) \pm \text { standard deviation } \\
(\mathbf{n}=3)\end{array}$ \\
\hline $\begin{array}{l}\text { Total } \\
\text { Inorganic } \\
\text { species }\end{array}$ & $\mathrm{Se}(\mathrm{IV})$ & $105 \pm 2$ \\
& $\mathrm{Se}(\mathrm{VI})$ & $1.5 \pm 0.1$ \\
Organic & Hydrophobic species & $1.5 \pm 0.1$ \\
species & Hydrophilic species & $96.2 \pm 2.3$ \\
\hline
\end{tabular}

An estimated safe and adequate daily dietary intake of Se has been established as 10-200 $\mu \mathrm{g}$ per day, depending on age. ${ }^{11}$ Considering the maximum value $(200 \mu \mathrm{g}$ per day) and total Se concentration $\left(105 \mu \mathrm{g} \mathrm{g}^{-1}\right)$, only $1.9 \mathrm{~g}$ (dry mass) of enriched adzuki bean sprouts should be consumed per day. The sum of Se species concentrations corresponded to $99 \%$ of the total Se concentration. Chemical speciation studies demonstrated that organic, mainly hydrophilic, Se species were the major constituents, corresponding to $93 \%$ of the total Se concentration. The inorganic Se species corresponded to $5.4 \%$ of the total Se concentration, with a percentage of Se(IV) $(1.4 \%)$ lower than that of Se(VI) (4.0\%). Because Se organic species are more bioavailable than inorganic Se species, a consumption of approximately $2.0 \mathrm{~g}$ of enriched adzuki bean sprouts corresponds to the maximum safe and adequate daily dietary intake of Se $(200 \mu \mathrm{g}$ per day).

\section{Conclusion}

The method applied for the Fe speciation in adzuki bean sprouts allowed to evaluate the enrichment efficiency of these agricultural products through a rapid procedure that uses the complexation of $\mathrm{Fe}(\mathrm{II})$ with antinutritional components present naturally in the plant matrix, which allowed to determine the concentrations of soluble and inorganic Fe. In the bean sprouts, it was verified that the enrichment increased the total, soluble, and inorganic Fe species concentrations, species that are potentially absorbed by the human organism, indicating the effectiveness of the proposed enrichment procedure.

An analytical strategy based on the combination of CPE as a preconcentration and separation method with GF AAS allowed the determination of organic (hydrophilic and hydrophobic) and inorganic (Se(IV) and Se(VI)) Se species in enriched adzuki bean sprouts. The developed methodology is simple and safe compared to other extraction procedures because it does not require exposure to organic compounds and includes a sustainable method of elemental preconcentration and speciation. The methodology enabled the identification and quantification of Se forms in the sprouts, showing that organic, mainly hydrophilic, Se species were predominant. Thus, because organic Se species are more bioavailable than inorganic Se species, enriched adzuki bean sprouts can be safely used as dietary supplements, and can be considered as an appropriate alternative to reduce $\mathrm{Se}$ deficiency.

\section{Acknowledgements}

Aline Pereira de Oliveira thanks the Fundação de Amparo à Pesquisa do Estado de São Paulo/FAPESP (2015/01128-6) for the fellowship provided. Juliana Naozuka thanks the FAPESP for financial support (2015/15510-0).

\section{Compliance with ethics requirements}

The author declares that they have no conflict of interest.

This article does not contain any studies with human or animal subjects.

\section{References}

1. McGILL JA. Michigan: Japan and azuki beans. Michigan Dry Bean Digest. 1995;19:4-7.

2. Sangronis E, Machado CJ. Influence of germination on the nutritional quality of Phaseolus vulgaris and Cajanus cajan. LWT Food Sci Technol. 2007;40(1):116-120.

3. Yuan L, Wu L, Yang C, Lv Q. Effects of iron and zinc foliar applications on rice plants and their grain accumulation and grain nutritional quality. J Sci Food Agr. 2013;93(2):254-261. 
4. Lintschinger J, Fuchs N, Moser J, et al. Selenium-enriched sprouts. A raw material for fortified cereal-based diets. J Agric Food Chem. 2000;48(11):5362-5368

5. Wei Y, Shohag MJI, Ying F, et al. Effect of ferrous sulfate fortification in germinated brown rice on seed iron concentration and bioavailability. Food Chem. 2013;138(2-3):1952-1958.

6. Davidsson L, Ziegler E, Zeder C, et al. Sodium iron EDTA [NaFe (III) EDTA] as a food fortificant: erythrocyte incorporation of iron and apparent absorption of zinc, copper, calcium, and magnesium from a complementary food based on wheat and soy in healthy infants. Am J Clin Nutr. 2005;81(1):104-109.

7. Alfthan $\mathrm{G}, \mathrm{Xu}$ GL, Tan WH, et al. Selenium supplementation of children in a selenium-deficient area in China. Biol Trace Elem Res. 2000;73(2):113-125.

8. Bravo L. Polyphenols: chemistry, dietary sources, metabolism, and nutritional significance. Nutr Rev. 1998;56:317-333.

9. Foster LH, Sumar S. Selenium in health and disease: a review. Crit Rev Food Sci Nutr. 1197;37(3):211-228.

10. Papp LV, Lu J, Holmgren A, et al. From selenium to selenoproteins: synthesis, identity, and their role in human health. Antioxid Redox Signal. 2007;9(7):775-806.

11. Chen S, Zhu S, Lu D. Solidified floating organic drop microextraction for speciation of selenium and its distribution in selenium-rich tea leaves and tea infusion by electrothermal vapourisation inductively coupled plasma mass spectrometry. Food Chemistry. 2015;169:156-161.

12. Tuzen M, Saygi KO, Soylak M. Separation and speciation of selenium in food and water samples by the combination of magnesium hydroxide coprecipitation-graphite furnace atomic absorption spectrometric determination. Talanta. 2007;71(1):424-429

13. Rayman MP, Infante HG, Sargent M. Food-chain selenium and human health: spotlight on speciation. Br J Nutr. 2008;100(2):238-253.

14. Lynch SR. Interaction of iron with other nutrients. Nutr Rev. 1997;55(4):102-110.

15. Oliveira AP, Naozuka J. Chemical speciation of iron in different varieties of beans (Phaseolus vulgaris L.): cooking effects. J Braz Chem Soc. 2015;26(10):2144-2149.

16. Oliveira AP, Naozuka J. Effects of iron enrichment of adzuki bean (vigna angularis) sprouts on elemental translocation, concentrations of proteins, distribution of $\mathrm{Fe}-$ metalloproteins, and Fe bioaccessibility. $J$ Braz Chem Soc. 2017;28(10).

17. Oliveira AP, Nomura CS, Naozuka J. Evaluation of selenium enrichment of adzuki bean (Vigna angularis) sprouts: Translocation, bioaccessibility and Se-protein speciation. Microchemical Journal. 2017;134:19-26.

18. Templeton DM, Ariese F, Cornelis R, et al. Guidelines for terms related to chemical speciation and fractionation of elements. Definitions, structural aspects, and methodological approaches (IUPAC Recommendations 2000). Pure and Applied Chemistry. 2000;72(8):1453-1470.

19. Machado ALDL, Barcelos MDFP, Teixeira AHR, et al. Avaliação de componentes químicos em brotos de Fabaceae para o consumo humano. Cienc Tecnol Aliment. 2009;33(4):1071-1078.

20. Naozuka J, Vieira EC, Nascimento AN, et al. Elemental analysis of nuts and seeds by axially viewed ICP OES. Food Chemistry. 2011;124(4):1667-1672.

21. Carreira RL, Ornellas CBD, Morais HA, et al. Efeito da precipitação pelo ácido tricloroacético (TCA) e da ultrafiltração sobre o perfil peptídico de hidrolisados de caseína. Ciênc Agrotec. 2003;7(2):414-421.

22. Quinteros A, Farré R, Lagarda M. Optimization of iron speciation (soluble, ferrous and ferric) in beans, chickpeas and lentils. Food Chemistry. 2001;75(3):365-370.

23. Kosse JS, Yeung AC, Gil A, et al. A rapid method for iron determination in fortified foods. Food Chemistry. 2001;75(3):371-376.

24. Sun M, Liu G, Wu Q (2013) Speciation of organic and inorganic selenium in selenium-enriched rice by graphite furnace atomic absorption spectrometry after cloud point extraction. Food Chem. 2013;141(1):6671.

25. Silva JCJ, Cadore S, Nobrega JA, et al. Dilute-and-shoot procedure for the determination of mineral constituents in vinegar samples by axially viewed inductively coupled plasma optical emission spectrometry (ICP OES). Food Addit Contam. 2007;24(2):130-139.

26. https://www.fda.gov/food/foodscienceresearch/laboratorymethods/ ucm2006954.htm

27. Carreira RL, Ornellas CBD, Morais HA, et al. Efeito da precipitação pelo ácido tricloroacético (TCA) e da ultrafiltração sobre o perfil peptídico de hidrolisados de caseína. Ciênc Agrotec. 2003;27:414-421.

28. Hallberg L, Rossander L, Skander AB. Phytates and the inhibitory effect of bran on iron absorption in man. American J Clin Nutr. 1987;45(5):988-996

29. Pallauf J, Rimbach G. Nutritional significance of phytic acid and phytase. Arch Anim Nutr. 1997;50(4):301-319.

30. Quirrenbach HR, Kanumfre F, Rosso ND, et al. Behaviour of phytic acid in the presence of iron(II) and iron(III). Ciênc Tecnol Aliment. 2009;9(1):24-32.

31. Chunhieng T, Pétritis K, Elfakir C, et al. Study of selenium distribution on the protein fractions of the Brazil nut, Bertholletia excels. J Agr Food Chem. 2004;52(13):4318-4322.

32. Santos HM, Capelo JL. Trends in ultrasonic-based equipment for analytical sample treatment. Talanta. 2007;73(5):795-802.

33. Montes-Bayón M, Molet MJD, González EB, et al. Evaluation of different sample extraction strategies for selenium determination in selenium-enriched plants (Allium sativum and Brassica juncea) and $\mathrm{Se}$ speciation by HPLC-ICP-MS. Talanta. 2006;68(4):1287-1293.

34. Correia PRM, Oliveira E, Oliveira PV. Simultaneous determination of manganese and selenium in serum by electrothermal atomic absorption spectrometry. Talanta. 2002;57(3):527-535.

35. Sounderajan S, Kumar GK, Udas AC. Cloud point extraction and electrothermal atomic absorption spectrometry of Se (IV)-3, 3'diaminobenzidine for the estimation of trace amounts of Se (IV) and Se (VI) in environmental water samples and total selenium in animal blood and fish tissue samples. J Hazard Mater. 2010;75(1-3):666-672.

36. Güler N, Maden M, Bakırdere S, et al. Speciation of selenium in vitamin tablets using spectrofluorometry following cloud point extraction. Food Chemistry. 2011;129(4):1793-1799.

37. Escaleira LA, Santelli RE, Oliveira EP, et al. Preconcentration procedure for determining trace amounts of $\mathrm{Ni}, \mathrm{Cd}, \mathrm{Pb}$ and $\mathrm{Cu}$ in highsalinity waters after cloud-point extraction. Int J Environ Anal Chem. 2009;89(7):515-527.

38. Ghambariana M, Yaminia Y, Saleha A, et al. A 16 orthogonal array design for the optimization of cloud point extraction for selenium 
determination in environmental and biological samples by tungstenmodified tube electrothermal atomic absorption spectrometry. Talanta. 2009;78(3):970-976.

39. Soruraddin MH, Heydari R, Puladvand M, et al. Anew spectrophotometric method for determination of selenium in cosmetic and pharmaceutical preparations after preconcentration with cloud point extraction. Int $J$ Anal Chem. 2011;1-8.
40. Gallignani M, Valero M, Brunetto MR, et al. Sequential determination of $\mathrm{Se}(\mathrm{IV})$ and $\mathrm{Se}(\mathrm{VI})$ by flow injection-hydride generation-atomic absorption spectrometry with $\mathrm{HCl}: \mathrm{HBr}$ microwave aided pre-reduction of Se(VI) to Se(IV). Talanta. 2000;52(6):1015-1024.

41. Pilon-Smits E, Quinn C. Selenium metabolism in plants. Berlin: Springer; 2010. 